Original

\title{
Association between periodontal status and idiopathic male infertility
}

\author{
Norbert Pásztor ${ }^{1)}$, Krisztina Kárpáti ${ }^{2)}$, János Szöllősi ${ }^{1)}$, Márk Keresztúri ${ }^{3)}$, \\ Zoltan Kozinszky ${ }^{4)}$, István Gorzós), and Márta Radnai')
}
${ }^{1)}$ Department of Obstetrics and Gynecology, Medical Faculty, University of Szeged, Szeged, Hungary
${ }^{2)}$ Department of Prosthodontics, Faculty of Dentistry, University of Szeged, Szeged, Hungary
${ }^{3)}$ Faculty of Dentistry, University of Szeged, Szeged, Hungary
${ }^{4}$ Department of Obstetrics and Gynaecology, Blekinge Hospital, Karlskrona, Sweden
${ }^{5}$ Department of Periodontology, Faculty of Dentistry, University of Szeged, Szeged, Hungary
${ }^{6}$ Department of Prosthodontics, Department of Dentistry, Oral and Maxillofacial Surgery, University of Pécs Medical School, Pécs, Hungary

(Received October 27, 2015; Accepted February 3, 2016)

\begin{abstract}
About 30\% of male infertility cases are idiopathic. Previous studies reported a positive correlation between deep periodontal pockets and sperm sub-motility, which suggests that periodontitis might have a role in idiopathic semen abnormality pathospermia. We evaluated correlations between periodontal infection parameters and the results of sperm analysis of men with idiopathic infertility. In this observational study, semen quality and periodontal status were analyzed for 95 otherwise healthy men attending an andrology unit for sperm analysis. Half the men in the sperm pathology and normozoospermia groups $\mathbf{5 0 . 8 \%}$ and $\mathbf{5 0 \%}$, respectively) had poor periodontal status. Among the 95 participants, $38 \%$ had oligozoospermia, $28 \%$ had asthenozoospermia, $16 \%$ had cryptozoospermia, and $15 \%$ were classified as normozoospermic. Sperm pathology category was not associated with frequency of deep periodontal pockets or calculus. Bleeding on probing was significantly lower among men with asthenozoospermia than among those with normozoospermia. Poor periodontal status was not associated with any sperm pathology category or parameter. In contrast
\end{abstract}

Correspondence to Dr. Norbert Pásztor, 6725 Szeged, Semmelweis u. 1, Hungary

Fax:+36-62-545-711 E-mail: hirt78@gmail.com

doi.org/10.2334/josnusd.15-0586

DN/JST.JSTAGE/josnusd/15-0586 with previous findings, the present results indicate that pathospermia and poor semen quality are not associated with periodontal infection in men with idiopathic infertility. (J Oral Sci 58, 247-253, 2016)

Keywords: idiopathic male infertility; pathospermia; periodontal status; periodontitis.

\section{Introduction}

Gingivitis and chronic periodontitis are common chronic diseases in adults worldwide (1-3). Poor dental health can adversely affect a number of systemic conditions and diseases, such as cardiovascular diseases (4), diabetes (5), respiratory diseases (6), and inflammatory bowel diseases (7), and can even lead to preterm delivery $(8,9)$ and systemic disease (10-12). However, the associations between periodontal disease and sperm abnormalities have not been adequately investigated.

The estimated prevalence of infertility among couples of reproductive age is $15 \%$ (13), and almost half of such cases are attributable to disturbances in male fertility (14). Although the causes of male infertility have been extensively investigated, $25 \%$ of male infertility cases are idiopathic (14). Periodontitis might have a role in subfertility (15). A direct causal relationship was suspected between bacterial colonies in dental foci and therapy-resistant bacteriospermia (15). Furthermore, other studies reported a positive correlation between 
deep periodontal pockets and sperm submotility (16). However, no previous study focused on men with idiopathic infertility. Hence, we investigated the relationship between periodontal status and spermiogram parameters in men with idiopathic infertility.

\section{Materials and Methods}

Male patients seeking infertility evaluation were recruited at the Andrology Outpatient Clinic in the Department of Obstetrics and Gynaecology of the University of Szeged, Hungary, between 1 October 2010 and 30 July 2013. Sociodemographic data (age, place of residence, education level, and profession) and information on lifestyle factors (smoking, alcohol consumption, and drug abuse) were collected via a self-reported questionnaire, followed by andrological and periodontal examinations.

\section{Semen collection and analysis}

Semen was analyzed and classified according to the World Health Organization (WHO) criteria (17). After 3-5 days of abstinence, semen samples were obtained by masturbation and ejaculation into glass containers in a private room close to the laboratory. The samples were handled at room temperature $\left(22-25^{\circ} \mathrm{C}\right)$, and semen analysis began within $1 \mathrm{~h}$ after ejaculation. Sperm concentration, total sperm count, total sperm motility, and progressive and nonprogressive motility were assessed with phase-contrast optics at $\times 200$ magnification in a Makler counting chamber (FertiCAD Kft., Budapest, Hungary), as described in the WHO laboratory manual for the examination of human semen (17). Sperm morphology was determined at $\times 1,000$ magnification with oil immersion after Diff-Quik staining (Diff-Quik Staining Set, Medion Diagnostics AG, Düdingen, Switzerland). Progressive motility was specified as the proportion of actively moving spermatozoa. Nonprogressive motility was defined as the percentage of moving spermatozoa with no evidence of progression. Total motility was the sum of progressive and nonprogressive motility. Normozoospermia was classified as a normal ejaculation, as defined by WHO reference values, namely, a sperm cell concentration of $15 \times 10^{6} / \mathrm{mL}$ or greater, a total sperm count of $39 \times 10^{6}$ per ejaculate or greater, total motility of at least $40 \%$, and progressive motility of $32 \%$ or greater. Cryptozoospermia was diagnosed when spermatozoa were absent from a fresh preparation but were observed in a centrifuged pellet. Teratozoospermia was diagnosed when the proportion of sperm cells with normal morphology was less than $4 \%$. In cases of oligozoospermia (sperm concentration $<15$ $\times 10^{6} / \mathrm{mL}$ ) and asthenozoospermia (progressive motility
$<32 \%$ ), a blood sample was collected for measurement of hormone levels, and an ultrasound examination of the testes was performed. When sperm concentration was less than $1 \times 10^{6} / \mathrm{mL}$, screening for karyotyping and azoospermia factor microdeletion of the $\mathrm{Y}$ chromosome (AZFa /sY84,86/; AZFb /sY127,134/; AZFc/sY254,255/ regions) was also performed.

Only men with idiopathic infertility were enrolled in the study. Men were excluded from the study if they had a varicocele or testicular microlithiasis (confirmed by ultrasound examination), hypogonadism (verified by hormonal measurements), a genetic disorder (determined by chromosome analysis or molecular genetic investigations), or symptoms of genital infection. Patients with azoospermia (no spermatozoa in ejaculate) were also excluded because of the possibility of seminal duct obstruction or serious testicular abnormality.

\section{Periodontal examination}

Where it was impossible to measure probing depth (PD), wisdom teeth and radices were excluded from periodontal charting. The amount of plaque was recorded on a 0 to 3 scale on the "Ramfjord teeth" (\#16, 21, 24, 36, 41 , and 44) (18) at four surfaces per tooth, according to the criteria developed by Silness and Löe (19). If a Ramfjord tooth was missing, the adjacent molar, premolar, or central incisor was examined. PD was measured at six sites on each tooth (mesiobuccal, midbuccal, distobuccal, mesiolingual, midlingual, and distolingual) with a millimeter-scale Michigan periodontal probe (Hu-Friedy, Chicago, IL, USA). PD values were recorded in millimeters and rounded down to the nearest whole millimeter. Sulcus bleeding on probing (BOP) was classified as positive if bleeding occurred within $15 \mathrm{~s}$ after probing at any tooth site. Dental calculus was recorded dichotomously as present or absent. The number of missing teeth was also recorded. Poor periodontal status was defined as a probing depth of $\geq 4 \mathrm{~mm}$ for at least at one tooth site and BOP at $50 \%$ or more of teeth (8). Periodontal examination was repeated for 10 patients after an interval of 30 $\mathrm{min}$, and the intraclass correlation coefficient was 0.90 .

The dental characteristics of the oligozoospermia, asthenozoospermia, cryptozoospermia, and sperm pathology (men with any sperm abnormality) groups were compared with those of normozoospermic men (control group). Patients with oligo-asthenozoospermia were included in both the oligozoospermic and asthenozoospermic groups. The dentist was blinded to the andrological status of patients. All dental examinations were performed by one of two authors (M.R. and K.K.), both of whom are experienced in periodontal charting. 
Table 1 Characteristics of men with idiopathic male infertility treated at the Department of Obstetrics and Gynecology, University of Szeged (1 October 2010 through 30 July 2013)

\begin{tabular}{lcc}
\hline Age & $n=95(100 \%)$ & \\
Mean & & $35.1 \pm 5.7$ years \\
Minimum & 23.9 years \\
Maximum & 52.1 years \\
Place of residence & $n=95(100 \%)$ & \\
$\quad$ City & & $74(77.9 \%)$ \\
Village & $21(22.1 \%)$ \\
Educational level & \\
Primary school & & $1(1.1 \%)$ \\
Technical school & $28(29.5 \%)$ \\
Grammar school General secondary school & & $33(34.7 \%)$ \\
Higher education & $33(34.7 \%)$ \\
Occupation & & \\
Unemployed & & $2(2.1 \%)$ \\
Manual worker & & $41(43.1 \%)$ \\
Other & $23(24.2 \%)$ \\
Intellectual White-collar worker & $29(30.7 \%)$ \\
Smoking & $n=95(100 \%)$ & \\
No & & $69(72.6 \%)$ \\
Yes & & $26(27.4 \%)$ \\
5 cigarettes/day & $10(10.5 \%)$ \\
10 cigarettes/day & $10(10.5 \%)$ \\
20 cigarettes/day & $6(6.3 \%)$ \\
Past smoking & $44(46.3 \%)$ \\
Quit $>5$ years before & $13(13.7 \%)$ \\
BMI & & \\
$>30$ & & $16(16.8 \%)$ \\
$\leq 30$ & $79(83.2 \%)$ \\
\hline Date &
\end{tabular}

Data are presented as number (\%), unless otherwise indicated.

The study protocol was approved by the Regional and Institutional Human Medical Biological Research Ethics Committee of the University of Szeged, Hungary, in 2010 (Protocol No. 97/2010). Informed consent was obtained from all study participants.

\section{Statistical analyses}

Statistical analyses were performed with the SPSS for Windows program, Version 15 (SPSS Inc., Chicago, IL, USA). The Kolmogorov-Smirnov test confirmed that data for our study samples were not normally distributed. Continuous variables were expressed as mean \pm SD. The Mann-Whitney $U$ test was used for comparison of continuous variables, depending on case-control status (pathospermia vs. normal cases; poor periodontal status vs. healthy periodontium). Univariate comparisons of categorical variables were done with the $\chi^{2}$ test. The correlation between the sperm parameters and total number of teeth was determined by using Spearman rank correlations. Statistical significance was defined as a two-sided $P$ value of 0.05 or lower. Repeatability of the periodontal examination was assessed using intraclass correlation coefficients. Odds ratios for continuous variables were evaluated by univariate logistic regression and were adjusted for confounding factors (age, smoking status, and body mass index) in multiple logistic regression analysis.

\section{Results}

During the study period, 95 men were consecutively recruited into the study. Their sociodemographic characteristics are summarized in Table 1 . The average age of the participants was 35.1 years (range: 23-51 years). Overall, 26 men (27.4\%) smoked and $16.8 \%$ were obese, and $36(37.9 \%)$ were oligozoospermic and 27 (28.4\%) were asthenozoospermic (15 patients had both disorders). Cryptozoospermia was diagnosed in $15(15.8 \%)$ of the men, and 32 (33.7\%) men were normozoospermic. Some type of sperm abnormality was noted in $63(66.3 \%)$ men. Teratozoospermia was diagnosed in five men (5.2\%).

Periodontal examination results were analyzed in relation to spermiogram group (Table 2). The mean plaque index was 0.69 in the sperm pathology group and 0.63 in the control group. Among men with any type of sperm abnormality, average PD was $2.19 \mathrm{~mm}$ and BOP was observed at $55.5 \%$ of teeth; in normozoospermic men the respective values were $1.99 \mathrm{~mm}$ and $53.9 \%$. A PD of $\geq 4$ $\mathrm{mm}$ was more frequent in men with a sperm abnormality than in the control group, although the difference was not significant (44 [69.8\%] vs. 18 [56.3\%]). Sixty-two 
Table 2 Dental characteristics of men with idiopathic male infertility, according to sperm pathology, treated at the Department of Obstetrics and Gynecology, University of Szeged (1 October 2010 through 30 July 2013)

\begin{tabular}{|c|c|c|c|c|c|c|c|c|c|c|c|c|c|c|c|c|c|}
\hline & $\begin{array}{c}\text { Crypto- } \\
\text { zoospermia } \\
(n=15)\end{array}$ & $P$ value & $\begin{array}{c}\mathrm{OR} \\
(95 \% \mathrm{CI})\end{array}$ & $\begin{array}{c}\mathrm{AOR} \\
(95 \% \mathrm{Cl})\end{array}$ & $\begin{array}{c}\text { Astheno- } \\
\text { zoospermia } \\
(n=27)\end{array}$ & $P$ value & $\begin{array}{c}\mathrm{OR} \\
(95 \% \mathrm{CI})\end{array}$ & $\begin{array}{c}\mathrm{AOR} \\
(95 \% \mathrm{Cl})\end{array}$ & $\begin{array}{c}\text { Oligozoo- } \\
\text { spermia } \\
(n=36) \\
\end{array}$ & value & $\begin{array}{c}\mathrm{OR} \\
(95 \% \mathrm{Cl})\end{array}$ & $\begin{array}{c}\mathrm{AOR} \\
(95 \% \mathrm{CI})\end{array}$ & $\begin{array}{c}\text { Any sperm- } \\
\text { pathology } \\
(n=63)\end{array}$ & $P$ value & $\begin{array}{c}\mathrm{OR} \\
(95 \% \mathrm{Cl})\end{array}$ & $\begin{array}{l}\mathrm{AOR} \\
95 \% \mathrm{CI})\end{array}$ & $\begin{array}{c}\text { Normo- } \\
\text { zoospermia } \\
(n=32)\end{array}$ \\
\hline Plaqu & $0.66 \pm 0.40$ & 0.46 & $\begin{array}{c}1.32 \\
(0.39-4.39)\end{array}$ & $\begin{array}{c}2.39 \\
(0.55-10.45)\end{array}$ & $0.59 \pm 0.42$ & 0.79 & $\begin{array}{c}0.85 \\
(0.30-2.46)\end{array}$ & $(0.31-3.06)$ & $0.73 \pm 0.43$ & 13 & $\begin{array}{l}1.70 \\
.62-4.66)\end{array}$ & $\begin{array}{c}2.03 \\
(0.68-6.12)\end{array}$ & $0.69 \pm 0.42$ & .23 & $\begin{array}{c}1.43 \\
(0.56-3.66)\end{array}$ & $\begin{array}{c}1.94 \\
(0.68-5.48)\end{array}$ & $0.59 \pm 0.55$ \\
\hline $\mathrm{D}(\mathrm{n}$ & +06 & 0.72 & $\begin{array}{c}1.03 \\
(0.37-2.82)\end{array}$ & $\begin{array}{c}1.04 \\
(0.32-3.38)\end{array}$ & 73 & 0 & $\begin{array}{c}0.58 \\
(0.25-1.32)\end{array}$ & $\begin{array}{c}0.55 \\
(0.23-1.31)\end{array}$ & .58 & 0.07 & $\begin{array}{c}0.44 \\
(0.18-1.04)\end{array}$ & $\begin{array}{c}0.39 \\
(0.1-0.98)\end{array}$ & 68 & 17 & $\begin{array}{c}0.64 \\
(0.33-1.22)\end{array}$ & $\begin{array}{c}0.61 \\
(0.31-1.20)\end{array}$ & .61 \\
\hline & $10(66.7 \%)$ & 0.50 & $\begin{array}{c}1.56 \\
(0.43-5.60)\end{array}$ & $\begin{array}{c}2.28 \\
(0.46-11.23)\end{array}$ & $21(77.8 \%)$ & 0.08 & $\begin{array}{c}2.72 \\
(0.87-8.55)\end{array}$ & $\begin{array}{c}3.07 \\
(0.87-10.91)\end{array}$ & $(69.4 \%)$ & 0.26 & $\begin{array}{c}1.77 \\
(0.65-4.78)\end{array}$ & $\begin{array}{c}1.82 \\
(0.64-5.19)\end{array}$ & $4(69.8 \%)$ & 0.19 & $\begin{array}{c}1.80 \\
(0.75-4.35)\end{array}$ & $\begin{array}{c}1.89 \\
(0.74-4.83)\end{array}$ & $18(56.3 \%)$ \\
\hline $\begin{array}{l}\text { Average number } \\
\text { of } \mathrm{PD} \geq 4 \mathrm{~mm}\end{array}$ & $15.87 \pm 22.41$ & 0.50 & $\begin{array}{c}1.01 \\
(0.98-1.04)\end{array}$ & $\begin{array}{c}1.01 \\
(0.97-1.04)\end{array}$ & 57 & 0.98 & $\begin{array}{c}0.99 \\
(0.97-1.02)\end{array}$ & $\begin{array}{c}0.99 \\
(0.96-1.02)\end{array}$ & 41 & 0.54 & $\begin{array}{c}0.98 \\
(0.95-1.01)\end{array}$ & $\begin{array}{c}0.97 \\
(0.94-1.01)\end{array}$ & 25 & 0.66 & $\begin{array}{c}0.99 \\
(0.97-1.01)\end{array}$ & $\begin{array}{c}0.99 \\
(0.97-1.01)\end{array}$ & 1 \\
\hline & 73,301 & 0.24 & $\begin{array}{c}0.39 \\
(0.08-1.85)\end{array}$ & $\begin{array}{c}0.49 \\
(0.08-2.98)\end{array}$ & $(741 \%)$ & 0.32 & $\begin{array}{c}0.41 \\
(0.10-1.58)\end{array}$ & $\begin{array}{c}0.49 \\
(0.12-2.04)\end{array}$ & $7.8 \%)$ & 0.35 & $\begin{array}{c}0.50 \\
(0.14-1.85)\end{array}$ & $\begin{array}{c}0.61 \\
(0.16-2.36)\end{array}$ & $49(77.8 \%)$ & 0.41 & $\begin{array}{c}0.50 \\
(0.15-1.67)\end{array}$ & $\begin{array}{c}0.61 \\
(0.17-2.13)\end{array}$ & $28(87.5 \%)$ \\
\hline Missing teeth & $3.40 \pm 3.16$ & 0.86 & $\begin{array}{c}1.00 \\
(0.82-1.23)\end{array}$ & $\begin{array}{c}0.90 \\
(0.67-1.22)\end{array}$ & $3.67 \pm 3.04$ & 0.72 & $\begin{array}{c}1.03 \\
(0.87-1.23)\end{array}$ & $\begin{array}{c}0.97 \\
(0.80-1.19)\end{array}$ & $78 \pm 3.44$ & 0.76 & $\begin{array}{c}1.04 \\
(0.89-1.21)\end{array}$ & $\begin{array}{c}1.01 \\
(0.84-1.21)\end{array}$ & $3.48 \pm 3.15$ & 0.95 & $\begin{array}{c}1.01 \\
(0.88-1.16)\end{array}$ & $\begin{array}{c}0.97 \\
(0.81-1.15)\end{array}$ & $3.38 \pm 2.95$ \\
\hline $\begin{array}{l}\text { Frequency of } \\
\text { BOP/teeth (\%) }\end{array}$ & $17.33 \pm 7.95$ & 0.21 & $\begin{array}{c}1.05 \\
(0.97-1.14)\end{array}$ & $\begin{array}{c}1.04 \\
(0.94-1.14)\end{array}$ & 13 & 0.046 & $\begin{array}{c}0.94 \\
(0.88-1.01)\end{array}$ & $\begin{array}{c}0.93 \\
(0.87-1.00)\end{array}$ & . & 0.14 & $\begin{array}{c}0.96 \\
(0.90-1.02)\end{array}$ & $\begin{array}{c}0.94 \\
(0.88-1.01)\end{array}$ & \pm 8.07 & 0.44 & $\begin{array}{c}0.98 \\
(0.93-1.04)\end{array}$ & $\begin{array}{c}0.97 \\
(0.91-1.03)\end{array}$ & .13 \\
\hline $\begin{array}{l}\text { Frequency of } \\
\text { BOP }(\%)\end{array}$ & $.27 \pm 30.89$ & 0.46 & $\begin{array}{c}1.01 \\
(0.99-1.03)\end{array}$ & $\begin{array}{c}1.01 \\
(0.99-1.03)\end{array}$ & $52.04 \pm 29.39$ & 0.57 & $\begin{array}{c}0.99 \\
(0.98-1.01)\end{array}$ & $\begin{array}{c}1.00 \\
(0.98-1.01)\end{array}$ & $48.00 \pm 30.43$ & 0.29 & $\begin{array}{c}0.99 \\
(0.98-1.01)\end{array}$ & $\begin{array}{c}0.99 \\
(0.98-1.01)\end{array}$ & $53.90 \pm 30.40$ & 0.74 & $\begin{array}{c}1.00 \\
(0.98-1.01)\end{array}$ & $\begin{array}{c}1.00 \\
(0.98-1.01)\end{array}$ & 55.47 \\
\hline $\begin{array}{l}\text { Frequency of BOP } \\
\geq 50 \%(n(\%))\end{array}$ & $(66.7 \%)$ & 1.00 & $\begin{array}{c}1.20 \\
(0.33-4.36)\end{array}$ & $\begin{array}{c}1.19 \\
(0.26-5.49)\end{array}$ & $14(51$ & 0 & $\begin{array}{c}0.65 \\
(0.23-1.83)\end{array}$ & $\begin{array}{c}0.58 \\
(0.19-1.77)\end{array}$ & $7(47.2 \%)$ & 02 & $\begin{array}{c}0.54 \\
(0.20-1.42)\end{array}$ & $\begin{array}{c}0.48 \\
(0.17-1.36)\end{array}$ & $(55.6 \%)$ & 0.66 & $\begin{array}{c}0.75 \\
(0.3-1.79)\end{array}$ & $\begin{array}{c}0.70 \\
(0.28-1.76)\end{array}$ & $(62.5 \%)$ \\
\hline $\begin{array}{l}\text { Frequency of } \\
\text { BOP } \geq 50 \%+\text { PD } \\
\geq 4 \mathrm{~mm}(n(\%))\end{array}$ & $7(46.7 \%)$ & 0.55 & $\begin{array}{c}1.13 \\
(0.33-3.86)\end{array}$ & $\begin{array}{c}1.09 \\
(0.26-4.62)\end{array}$ & $11(40.7 \%)$ & 1.00 & $\begin{array}{c}0.88 \\
(0.31-2.49)\end{array}$ & $\begin{array}{c}0.74 \\
(0.24-2.28)\end{array}$ & $14(38.9 \%)$ & 0.81 & $\begin{array}{c}0.82 \\
(0.31-2.15)\end{array}$ & $\begin{array}{c}0.62 \\
(0.22-1.78)\end{array}$ & $26(41.3 \%)$ & 10.83 & $\begin{array}{c}0.90 \\
(0.38-2.14)\end{array}$ & $\begin{array}{c}0.81 \\
(0.33-2.00)\end{array}$ & $14(43.8 \%)$ \\
\hline
\end{tabular}

Data from all sperm pathology groups were compared with those from the normozoospermia group (the controls). $P$ values were calculated with the Mann-Whitney $U$ test, for continuous variables (expressed as mean $\pm \mathrm{SD}$ ), and differences between categorical variables, expressed as number $(n)$ and rate $(\%)$, were assessed by the $\chi^{2}$ test. Odds ratios for continuous variables were estimated by univariate logistic regression, and adjusted odds ratios were calculated by multiple logistic regression adjusted for age, smoking status, and body mass index. Statistical significance was defined as a two-sided $P$ value of 0.05 or lower.

logistic regression adjusted for age, smoking status, and body mass index. Statistical significance was defined as
(A)OR: (adjusted) odds ratio; $95 \%$ CI: 95\% confidence interval; PD: probing depth; BOP: bleeding on probing.

men had a probing depth $\geq 4 \mathrm{~mm}$ and 15 had a probing depth $\geq 6 \mathrm{~mm}$. Thus, two-thirds of participants had deep pockets and almost one-sixth had very deep pockets. In addition, the frequency of poor periodontal status, defined as concomitant bleeding on probing at $\geq 50 \%$ of teeth and presence of at least one tooth with a PD $\geq 4$ $\mathrm{mm}$ ( $\mathrm{POB} \geq 50 \%+\mathrm{PD} \geq 4 \mathrm{~mm}$ in Table 2 ) was similar in the sperm pathology group and normozoospermia groups (50.8\% and 50\%, respectively). Almost all periodontal characteristics studied did not significantly differ between the controls and any spermiogram group (i.e., men with diagnoses of crypto-, astheno-, or oligozoospermia). Surprisingly, BOP per tooth was significantly lower among men with asthenozoospermia, as compared with the other groups. In addition, teratozoospermia was not significantly associated with adverse periodontal status (data not shown in tables). Poor periodontal status was not significantly associated with any sperm abnormality or sperm parameter (Table 3).

\section{Discussion}

We found no correlation between poor periodontal status and any form of idiopathic pathozoospermia in the present study. Poor periodontal status had no significant effect on semen quality. Two previous studies reported evidence of a possible connection between periodontal characteristics and sperm pathology $(16,20)$. Klinger et al. (16) investigated 75 men attending an in vitro fertilization clinic. Deep periodontal pockets and clinical attachment loss were significantly correlated with sperm submotility. However, there was no such correlation with oligozoospermia or normozoospermia. A similar study, by Nwhator et al. (20), investigated 76 infertile men and found a significant association between deeper periodontal pockets and suboptimal sperm count in men aged 33-38 years, and a correlation between poor oral hygiene and low sperm concentration. However, there was no correlation between oral health and sperm motility. It is important to note that neither study screened potential participants on the basis of cause of infertility $(16,20)$. In addition, spermiogram results were categorized by using earlier reference values for human semen analysis, which were subsequently revised in 2010 (17). Thus, it is difficult to draw conclusions from these conflicting results on associations of chronic gingivitis/periodontitis with male infertility.

Because the duration of spermatogenesis (i.e., from spermatogonium to spermatozoa production) is 74 days in humans (21), we did not assess clinical attachment loss (CAL) in our study. CAL mainly reflects previous periodontal processes and may have a noninfectious cause (e.g., unsatisfactory tooth brushing technique). In addition, not all gingivitis sites develop CAL (22). Our statistical analyses included BOP and PD as the main periodontal parameters. The selection of these variables was based on the design of previous studies. BOP is a known marker of periodontal inflammation (23-25). A PD $\geq 4 \mathrm{~mm}$ is considered "critical probing depth" (26), while lesser PD values are regarded as normal (27). Moreover, BOP and PD are significant factors in 
Table 3 Periodontal status and sperm parameters of men with idiopathic male infertility treated at the Department of Obstetrics and Gynecology, University of Szeged (1 October 2010 through 30 July 2013)

\begin{tabular}{|c|c|c|c|c|c|c|}
\hline & \multicolumn{2}{|c|}{$\begin{array}{l}\text { Poor periodontal status } \\
\qquad(n=48)\end{array}$} & \multicolumn{2}{|c|}{$\begin{array}{l}\text { Healthy periodontium } \\
\qquad(n=47)\end{array}$} & \multirow[t]{2}{*}{$P$ value } & \multirow{2}{*}{$\begin{array}{c}\text { OR } \\
(95 \% \mathrm{CI})\end{array}$} \\
\hline & $n$ & $\%$ & $n$ & $\%$ & & \\
\hline Cryptozoospermia & 9/27 & 33.3 & $6 / 20$ & 30.0 & 1.00 & $\begin{array}{c}1.17 \\
(0.33-4.06)\end{array}$ \\
\hline Asthenozoospermia & $11 / 29$ & 37.9 & $16 / 30$ & 53.3 & 0.299 & $\begin{array}{c}0.53 \\
(0.19-1.51)\end{array}$ \\
\hline Oligozoospermia & $15 / 33$ & 45.5 & $21 / 35$ & 60.0 & 0.33 & $\begin{array}{c}0.56 \\
(0.21-1.46)\end{array}$ \\
\hline Any sperm pathology & $30 / 48$ & 62.5 & $33 / 47$ & 70.2 & 0.516 & $\begin{array}{c}0.707 \\
(0.30-1.66)\end{array}$ \\
\hline Normal morphology $(\%)($ mean \pm SD $)$ & \multicolumn{2}{|c|}{$50.06 \pm 19.42$} & \multicolumn{2}{|c|}{$49.71 \pm 13.13$} & 0.599 & \\
\hline Motility $(\%)($ mean \pm SD) & \multicolumn{2}{|c|}{$51.56 \pm 22.90$} & \multicolumn{2}{|c|}{$50.33 \pm 18.40$} & 0.484 & \\
\hline Progressive motility $(\%)($ mean \pm SD $)$ & \multicolumn{2}{|c|}{$47.41 \pm 23.17$} & \multicolumn{2}{|c|}{$46.23 \pm 18.94$} & 0.570 & \\
\hline Nonprogressive motility (\%) (mean \pm SD) & \multicolumn{2}{|c|}{$4.95 \pm 4.96$} & \multicolumn{2}{|c|}{$3.82 \pm 3.34$} & 0.133 & \\
\hline Sperm concentration & \multicolumn{2}{|c|}{$48.36 \pm 48.59$} & \multicolumn{2}{|c|}{$44.612 \pm 47.02$} & 0.899 & \\
\hline $\begin{array}{l}\text { Total sperm number (concentration } \times \text { semen } \\
\text { volume) (millions) }\end{array}$ & \multicolumn{2}{|c|}{$175.70 \pm 190.82$} & \multicolumn{2}{|c|}{$202.97 \pm 231.52$} & 0.470 & \\
\hline
\end{tabular}

$P$ values were calculated with the Mann-Whitney $U$ test, for continuous variables (expressed as mean $\pm \mathrm{SD}$ ), and differences between categorical variables, expressed as number $(n)$ and rate (\%), were assessed by the $\chi^{2}$ test. Statistical significance was defined as a two-sided $P$ value of 0.05 or lower. 95\% CI: $95 \%$ confidence interval.

assessing the risk of periodontitis recurrence and activity (24). In this study, we elected to record plaque amount on the Ramfjord teeth only, as Löe and colleagues reported that plaque is not the only factor associated with progression of chronic periodontitis (28). In their study, most patients $(81 \%)$ exhibited only moderate progression, despite poor plaque control and gingival inflammation in all participants. Moreover, the present partial-mouth examination reduced examination time, which increased patient convenience and reduced examiner fatigue (29). Data for other variable were collected under full-mouth conditions.

Smoking is one of the most common lifestyle factors that adversely affects periodontal and andrological characteristics. It is a main risk factor for periodontal disease (30) and may have a negative impact on fertility. Tobacco exposure has a detrimental effect on sperm production and motility $(31,32)$ and induces sperm DNA damage (33). In our study sample, $27.4 \%$ of patients were smokers, but there was no significant difference in the proportion of smokers between study groups. Previous studies found that smoking cessation improves periodontal health (34) and has beneficial effects on sperm characteristics (35); thus, patients should be strongly advised to quit smoking.

A number of pathological mechanisms by which periodontal inflammation affects semen quality have been proposed. A previous study found a correlation between antibiotic-resistant bacteriospermia and presence of focal dental bacterial colonies resulting from bacteriemia in the oral cavity (15). Bacteriospermia was eliminated by dental treatment, and post-treatment sperm parameters were better than those in a control group. In contrast, another study found no association between presence of bacteria in semen and sperm parameters (36). Hence, bacteriospermia was not investigated in our research.

Pathogens can cause a remote pathogenic effect by direct action via bacteriemia and by inducing production of several circulating cytokines (37). Increased levels of circulating cytokines, caused by periodontal disease, can trigger C-reactive protein production in the liver $(38,39)$. Similar inflammatory molecules are important in regulating the blood-testis barrier, which affects the function of Sertoli cells. Tumor necrosis factor-alpha, transforming growth factor- $\beta 3$ (40), and interleukin-1 can disturb blood-testis barrier dynamics (41). Interleukin-6 alters blood-testis barrier function by inhibiting protein degradation (42). It should be noted however that because systemic inflammatory markers are not specific to periodontal disease and reflect inflammation from all sources, it is difficult to determine the specific effects of periodontitis. Eberhard et al. (43) found a systemic increase in inflammatory markers, while a recent study by Kinane et al. (44) did not show a similar correlation between short-term experimentally induced gingivitis, bacteriemia, and systemic cytokine levels. In any case, our results indicate that poor periodontal status has no remote effect on sperm production or sperm parameters, since poor oral hygiene did not appear to be linked to adverse sperm parameters in idiopathic infertility. The differences between past $(16,20)$ and present findings 
might be attributable to the stricter diagnostic criteria used for periodontal conditions and pathospermia in our study.

Because some evidence supports a link between inflammatory molecular mechanisms and the pathological profile of spermiograms, it was logical to examine the potential association between periodontal status in infertile men and the results of sperm analysis. In conclusion, although there is a connection between male infertility and other oral pathologies, poor periodontal status was not associated with infertility among men without genital infections or other apparent causes of infertility.

\section{Acknowledgments}

The authors would like to express their gratitude to Dr. Krisztina Boda, for her invaluable advice concerning the statistical evaluation of the data, and to nurses Zsuzsanna Szél, Krisztina Bella, Mária Kiss Juhászné, Éva Kiss, and Lenke Varnyú, who assisted with patient management and administration.

\section{Conflicts of interest and source of funding statement}

The authors declare that there was no institutional, private, or corporate financial support for the present study. No external funding, apart from the support of the authors' institution, was available for this study.

\section{References}

1. Reich E (2001) Trends in caries and periodontal health epidemiology in Europe. Int Dent J 51, 392-398.

2. Albandar JM, Rams TE (2002) Global epidemiology of periodontal diseases: an overview. Periodontol 2000 29, 7-10.

3. Eke PI, Dye BA, Wei L, Thornton-Evans GO, Genco RJ (2012) Prevalence of periodontitis in adults in the United States: 2009 and 2010. J Dent Res 91, 914-920.

4. Kebschull M, Demmer RT, Papapanou PN (2010) "Gum bug, leave my heart alone!"--epidemiologic and mechanistic evidence linking periodontal infections and atherosclerosis. J Dent Res 89, 879-902.

5. Saremi A, Nelson RG, Tulloch-Reid M, Hanson RL, Sievers ML, Taylor GW et al. (2005) Periodontal disease and mortality in type 2 diabetes. Diabetes Care 28, 27-32.

6. Azarpazhooh A, Leake JL (2006) Systematic review of the association between respiratory diseases and oral health. J Periodontol 77, 1465-1482.

7. Vavricka SR, Manser CN, Hediger S, Vögelin M, Scharl M, Biedermann L et al. (2013) Periodontitis and gingivitis in inflammatory bowel disease: a case-control study. Inflamm Bowel Dis 19, 2768-2777.

8. Radnai M, Gorzó I, Urbán E, Eller J, Novák T, Pál A (2006) Possible association between mother's periodontal status and preterm delivery. J Clin Periodontol 33, 791-796.

9. Chambrone L, Guglielmetti MR, Pannuti CM, Chambrone LA (2011) Evidence grade associating periodontitis to preterm birth andor low birth weight: I. A systematic review of prospective cohort studies. J Clin Periodontol 38, 795-808.

10. Seymour GJ, Ford PJ, Cullinan MP, Leishman S, Yamazaki K (2007) Relationship between periodontal infections and systemic disease. Clin Microbiol Infect 13, Suppl 4, 3-10.

11. Otomo-Corgel J, Pucher JJ, Rethman MP, Reynolds MA (2012) State of the science: chronic periodontitis and systemic health. J Evid Based Dent Pract 12, 20-28.

12. Tonetti MS, Van Dyke TE (2013) Periodontitis and atherosclerotic cardiovascular disease: consensus report of the Joint EFP/AAP Workshop on Periodontitis and Systemic Diseases. J Periodontol 84, S24-29.

13. Juul S, Karmaus W, Olsen J (1999) Regional differences in waiting time to pregnancy: pregnancy-based surveys from Denmark, France, Germany, Italy and Sweden. Hum Reprod $14,1250-1254$.

14. Jung JH, Seo JT (2014) Empirical medical therapy in idiopathic male infertility: promise or panacea? Clin Exp Reprod Med 41, 108-114.

15. Bieniek KW, Riedel HH (1993) Bacterial foci in the teeth, oral cavity, and jaw--secondary effects (remote action) of bacterial colonies with respect to bacteriospermia and subfertility in males. Andrologia 25, 159-162.

16. Klinger A, Hain B, Yaffe H, Schonberger O (2011) Periodontal status of males attending an in vitro fertilization clinic. J Clin Periodontol 38, 542-546.

17. World Health Organization (2010) WHO laboratory manual for the examination and processing of human semen. 5th ed, WHO Press, Geneve.

18. Ramfjord SP (1959) Indices for prevalence and incidence of periodontal disease. J Periodontol 30, 51-59.

19. Silness J, Löe H (1964) Periodontal disease in pregnancy. II. Correlation between oral hygiene and periodontal condition. Acta Odontol Scand 22, 121-135.

20. Nwhator SO, Umeizudike KA, Ayanbadejo PO, Opeodu OI, Olamijulo JA, Sorsa T (2014) Another reason for impeccable oral hygiene: oral hygiene-sperm count link. J Contemp Dent Pract 15, 352-358.

21. Amann RP (2008) The cycle of the seminiferous epithelium in humans: a need to revisit? J Androl 29, 469-487.

22. Armitage GC, Research, Science and Therapy Committee of the American Academy of Periodontology (2003) Diagnosis of periodontal diseases. J Periodontol 74, 1237-1247.

23. Lang NP, Joss A, Orsanic T, Gusberti FA, Siegrist BE (1986) Bleeding on probing. A predictor for the progression of periodontal disease? J Clin Periodontol 13, 590-596.

24. Lang NP, Tonetti MS (2003) Periodontal risk assessment (PRA) for patients in supportive periodontal therapy (SPT). Oral Health Prev Dent 1, 7-16.

25. Radnai M, Pál A, Novák T, Urbán E, Eller J, Gorzó I (2009) Benefits of periodontal therapy when preterm birth threatens. J Dent Res 88, 280-284.

26. Lindhe J, Socransky SS, Nyman S, Haffajee AD, Westfelt E (1982) "Critical probing depth" in periodontal therapy. J Clin Periodontol 9, 323-336. 
27. Listgarten MA (1980) Periodontal probing: what does it mean? J Clin Periodontol 7, 165-176.

28. Löe H, Anerud A, Boysen H, Morrison E (1986) Natural history of periodontal disease in man. Rapid, moderate and no loss of attachment in Sri Lankan laborers 14 to 46 years of age. J Clin Periodontol 13, 431-445.

29. Mumghamba EG, Pitiphat W, Matee MI, Simon E, Merchant AT (2004) The usefulness of using Ramfjord teeth in predicting periodontal status of a Tanzanian adult population. J Clin Periodontol 31, 16-18.

30. Chrysanthakopoulos NA (2015) Risk factors for the progression of periodontal disease in a Greek adult population. J Investig Clin Dent doi: 10.1111/jicd.12199.

31. Richthoff J, Elzanaty S, Rylander L, Hagmar L, Giwercman A (2008) Association between tobacco exposure and reproductive parameters in adolescent males. Int J Androl 31, 31-39.

32. Lingappa HA, Govindashetty AM, Puttaveerachary AK, Manchaiah S, Krishnamurthy A, Bashir S et al. (2015) Evaluation of effect of cigarette smoking on vital seminal parameters which influence fertility. J Clin Diagn Res 9, EC13-15.

33. Potts RJ, Newbury CJ, Smith G, Notarianni LJ, Jefferies TM (1999) Sperm chromatin damage associated with male smoking. Mutat Res 423, 103-111.

34. Chambrone L, Preshaw PM, Rosa EF, Heasman PA, Romito GA, Pannuti CM et al. (2013) Effects of smoking cessation on the outcomes of non-surgical periodontal therapy: a systematic review and individual patient data meta-analysis. J Clin Periodontol 40, 607-615.

35. Santos EP, López-Costa S, Chenlo P, Pugliese MN, Curi S, Ariagno J et al. (2011) Impact of spontaneous smoking cessation on sperm quality: case report. Andrologia 43, 431-435.

36. Domes T, Lo KC, Grober ED, Mullen JB, Mazzulli T, Jarvi K (2012) The incidence and effect of bacteriospermia and elevated seminal leukocytes on semen parameters. Fertil Steril 97, 1050-1055.

37. Cullinan MP, Seymour GJ (2013) Periodontal disease and systemic illness: will the evidence ever be enough? Periodontol 2000 62, 271-286.

38. Noack B, Genco RJ, Trevisan M, Grossi S, Zambon JJ, De Nardin E (2001) Periodontal infections contribute to elevated systemic C-reactive protein level. J Periodontol 72, 12211227.

39. Paraskevas S, Huizinga JD, Loos BG (2008) A systematic review and meta-analyses on C-reactive protein in relation to periodontitis. J Clin Periodontol 35, 277-290.

40. Xia W, Wong EW, Mruk DD, Cheng CY (2009) TGF- $\beta 3$ and TNF- $\alpha$ perturb blood-testis barrier (BTB) dynamics by accelerating the clathrin-mediated endocytosis of integral membrane proteins: a new concept of BTB regulation during spermatogenesis. Dev Biol 327, 48-61.

41. Schell C, Albrecht M, Mayer C, Schwarzer JU, Frungieri MB, Mayerhofer A (2008) Exploring human testicular peritubular cells: identification of secretory products and regulation by tumor necrosis factor-alpha. Endocrinology 149, 1678-1686.

42. Zhang H, Yin Y, Wang G, Liu Z, Liu L, Sun F (2014) Interleukin-6 disrupts blood-testis barrier through inhibiting protein degradation or activating phosphorylated ERK in Sertoli cells. Sci Rep 4, 4260.

43. Eberhard J, Grote K, Luchtefeld M, Heuer W, Schuett H, Divchev D et al. (2013) Experimental gingivitis induces systemic inflammatory markers in young healthy individuals: a single-subject interventional study. PLoS One 8, e55265.

44. Kinane DF, Zhang P, Benakanakere M, Singleton J, Biesbrock A, Nonnenmacher C, He T (2015) Experimental gingivitis, bacteremia and systemic biomarkers: a randomized clinical trial. J Periodont Res 50, 864-869. 